\title{
"Amor à mineira" - cultura do consumo e traços da cultura mineira nas comemorações do Dia dos Namorados
}

\section{"Amor à mineira" - culture of consumption and traits of Minas Gerais culture in the commemorations of the Valentine's Day}

\author{
Marcelo de Rezende Pinto ${ }^{1}$, Danielle Ramos de Miranda Pereira ${ }^{2}$, \\ Daniela Goes Paraiso Lacerda ${ }^{3}$
}

\begin{abstract}
Resumo
Este artigo apresenta resultados de uma pesquisa empírica conduzida com o objetivo de analisar as articulações entre o consumo e o universo cultural do estado de Minas Gerais, Brasil, no contexto das comemorações de uma importante data do comércio varejista - o Dia dos Namorados. Na revisão da literatura foram contempladas discussões acerca das características da cultura do consumo, da Consumer Culture Theory (CCT) e de traços da cultura mineira. Foram conduzidas 10 entrevistas em profundidade com o auxílio de um roteiro semiestruturado de entrevista, cujas transcrições foram analisadas por meio da técnica de Análise de Conteúdo. Os resultados permitem afirmar que o Dia dos Namorados é carregado de sentimentos positivos, característicos do romantismo envolvendo a data, algo que é representado pela presença marcante das palavras "afeto", "atenção", "cuidado", "amor", "carinho", "sentimento", entre outras. Percebeu-se também a presença destacada tanto de atos e comportamentos ligados à presença de presentes e aspectos experienciais do consumo diretamente atrelados a todos esses sentimentos. Em paralelo, identificou-se traços característicos da cultura mineira como apego às tradições, à parcimônia e à sobriedade. Tudo isso parece ratificar a noção de que tanto a cultura do consumo como a cultura mineira permeiam essa data.
\end{abstract}

Palavras-chave: Cultura do consumo; Dia dos Namorados; Cultura mineira.

\begin{abstract}
This paper presents results of an empirical research conducted with the objective of analyzing the links between the consumption and the cultural universe of the state of Minas Gerais, Brazil, in the context of celebrations of an important date of the retail trade - Valentine's Day. In the review of the literature, discussions about the characteristics of the consumption culture, the Consumer Culture Theory (CCT) and traits of the Minas Gerais culture were considered. Ten in-depth interviews were conducted with the help of a semi-structured interview script, whose transcriptions were analyzed
\end{abstract}

\footnotetext{
${ }^{1}$ Doutorado em Administração pela Universidade Federal de Minas Gerais (UFMG), Belo Horizonte, Minas Gerais, Brasil. E-mail: marcrez@hotmail.com

2 Doutorado em Demografia pela Universidade Federal de Minas Gerais, Belo Horizonte, Minas Gerais, Brasil. Pesquisadora da Fundação João Pinheiro (FJP), Belo Horizonte, Minas Gerais, Brasil. E-mail: danielle.mirandapereira@gmail.com

${ }^{3}$ Mestrado em Economia pela Universidade Federal de Minas Gerais, Belo Horizonte, Minas Gerais, Brasil. Pesquisadora da Fundação João Pinheiro, Belo Horizonte, Minas Gerais, Brasil. E-mail: daniela.lacerda@fjp.mg.gov.br
} 
using the Content Analysis technique. The results allow us to affirm that Valentine's Day is loaded with positive feelings, characteristic of romanticism involving the date, something that is represented by the striking presence of the words "affection", "attention", "care", "love", "affection", "feeling", among others. It was also noticed the presence of both acts and behaviors linked to the presence of gifts and experiential aspects of consumption directly linked to all these feelings. In parallel, characteristic features of the Minas Gerais culture were identified as attachment to traditions, parsimony and sobriety. All this seems to confirm the notion that both the culture of consumption and the culture of Minas Gerais permeate that date.

Keywords: Culture of consumption; Valentine's Day; Culture of Minas Gerais.

\section{Introdução}

Ao jogar luz sobre o fenômeno do consumo, algumas constatações interessantes parecem emergir. Ao mesmo tempo em que o consumo faz parte do cotidiano do ser humano desde o início de sua existência, ele pode ser considerado um dos fenômenos mais importantes das sociedades modernas (McCRACKEN, 2003; BARBOSA, 2006; DESJEUX, 2011). Nesse sentido, a partir desses autores pode-se chegar à constatação de que, observando a vida moderna e as relações entre os produtos e as pessoas, podem-se identificar características individuais, coletivas e culturais, que revelam o comportamento de consumo individual e dos grupos, bem como os símbolos e as imagens que os produtos refletem na vida dos indivíduos.

Sendo assim, o consumo é moldado, dirigido e constrangido em todos os aspectos por considerações culturais (McCRACKEN, 2003). Entende-se, portanto, que um melhor entendimento das relações sociais envolvendo o consumo deve levar em conta o entendimento da cultura dos indivíduos envolvidos nessas diversas relações. Essa constatação parece ter aderência ao que foi proposto por Arvidsson (2008) ao elencar razões para a incorporação dos estudos culturais em marketing. Em primeiro lugar, a partir dos anos 1980, com a virada interpretativa dos estudos do campo, diversas visões consolidadas como processamento de informações, por exemplo, começaram a ser desafiadas por novas teorias oriundas das Ciências Sociais e Humanas. Esse contexto levou a um maior interesse pelos estudos culturais. Em segundo lugar, a tradição dos estudos culturais se tornou mais próxima às necessidades de pesquisa do campo do marketing e menos hostil à cultura do consumidor. Por fim, os estudos culturais permitem aos estudiosos de marketing legitimar sua disciplina frente ao radicalismo que marcaram o universo acadêmico americano nos anos 1990.

Cabe salientar também que têm sido ignorados pelos pesquisadores brasileiros muitos dos mecanismos de mediação aos quais se encontram submetidos à cultura material e seu papel no mundo contemporâneo. Assim, a busca pelo entendimento das experiências de consumo oferece um imbricado conjunto de temáticas que permite conhecer as peculiaridades e detalhes da cultura regional. E mais, como o contexto cultural socialmente construído contribui para "talhar" as escolhas, os significados, o simbolismo e as mediações das experiências de consumo no cotidiano dos indivíduos (BARBOSA; CAMPBELL, 2006; MIGUELES, 2007; MILLER, 2013).

Entre as diversas situações de consumo presentes no cotidiano dos indivíduos no contexto da sociedade de consumo, é interessante considerar que algumas datas comemorativas, por exemplo, Natal, Dia das Mães, Dia dos Namorados, entre outras, incorporam uma série de elementos simbólicos, bem como rituais que acabam por reforçar muitos dos valores e estruturas dessa sociedade. Dito de outra forma, essas datas parecem estar impregnadas de uma série de significados, simbolismos, rituais e atributos que contribuem por explicar muitas questões. Pode-se, assim, perceber uma lacuna nos estudos de cultura e consumo no Brasil que lancem luz sobre a forma como a comemoração dessas datas comemorativas se articulam com os traços culturais específicos de regiões no Brasil. 
Dado o exposto, surgiu o interesse em empreender uma pesquisa empírica com o objetivo de analisar as articulações entre o consumo e o universo cultural do estado de Minas Gerais, Brasil. Para investigar essa questão, achou-se conveniente lançar mão de uma das datas comemorativas do calendário varejista - o Dia dos Namorados - pelo fato de que essa ocasião contemplaria elementos tanto relacionados ao consumo como estariam latentes valores e traços concernentes ao ambiente cultural de Minas Gerais.

A execução da pesquisa se justifica por alguns motivos. Em primeiro lugar, porque o trabalho tem por base teórica o campo de estudos originados na teoria da cultura do consumo. Em estudos desse campo, parte-se de uma exploração da distribuição heterogênea dos significados e a multiplicidade de grupos e manifestações culturais que existem nas diversas formações sócio-históricas atuais. Em que pese a constatação de que é possível encontrar na literatura alguns trabalhos que articulem a relação entre questões culturais e consumo (SALOMÃO et al., 2020; LACERDA; PAIVA JÚNIOR; MELLO, 2020; LUIZ et al., 2018; DALMORO, 2015), não se pode negar que os rituais e suas relações com a cultura regional e de consumo envolvidas em uma comemoração parece ter uma alta carga de simbolismo. No caso do Dia dos Namorados, há diversos pontos que compõem um fenômeno que oferece diversos elementos para uma profícua discussão para o campo do consumo. Ademais, relatos de trabalhos como este podem contribuir para a formação de uma massa crítica de conhecimentos para explicar fenômenos de consumo ligados à cultura nacional e regional que envolvem complexidade, além de uma série de ambiguidades e idiossincrasias.

$\mathrm{O}$ artigo foi estruturado em quatro seções, além dessa introdução. A seção de revisão da literatura se dedica a explanar questões relativas à cultura do consumo e traços da cultura mineira. A seção seguinte contempla as discussões atinentes ao percurso metodológico adotado no estudo. Em seguida, optou por incluir a seção de análise dos resultados com ênfase nas categorias emergentes na fase de análise de dados. $\mathrm{O}$ artigo termina com pontos relevantes que compuseram as considerações finais.

\section{Revisão da literatura}

\section{Cultura do consumo}

O homem precisa de bens para comunicar-se com os outros e para tentar compreender o que se passa à sua volta. As duas necessidades podem ser convertidas em uma só, já que a comunicação somente pode ser construída em um sistema estruturador de significados (DOUGLAS; ISHERWOOD, 2006). Desse modo, toma corpo uma espécie de subcampo, que atravessa as Ciências Sociais com o propósito de buscar compreender com profundidade o estudo das relações pessoa-objeto, levandose em consideração que os bens, ao mesmo tempo em que são uma instância da cultura material, também são uma oportunidade para a expressão do esquema categórico estabelecido pela cultura (McCRACKEN, 2003).

Nesse contexto, o termo cultura do consumo refere-se à forma dominante da reprodução cultural desenvolvida no Ocidente durante a modernidade. Ou seja, segundo Slater (2002, p. 17), essa cultura do consumo:

[...] está ligada a valores, práticas e instituições fundamentais que definem a modernidade ocidental, como a opção, o individualismo e as relações de mercado, a cultura de consumo não é a única maneira de realizar o consumo e reproduzir a vida cotidiana, mas é, com certeza, o modo dominante, e tem um alcance prático e uma profundidade ideológica que lhe permite estruturar e subordinar todas as outras.

Slater (2002) enfatiza que o tema central da cultura do consumo é o modo pelo qual ela articula as questões no tocante ao modo como devemos ou queremos viver, à forma de organização da sociedade. Isso tudo é feito no plano da vida cotidiana: a estrutura material e simbólica dos lugares onde 
vivemos e nosso modo de viver nesses lugares, o alimento que comemos, as roupas que usamos, os tipos de escassez e desigualdade que sofremos, e assim por diante.

Se a cultura do consumo tem fortes vínculos com a vida moderna como um todo, é o próprio Slater (2002) que tenta sintetizar algumas características por meio das quais a cultura de consumo tem sido identificada: a cultura do consumo é cultura de consumo; a cultura do consumo é cultura de uma sociedade de mercado; a cultura do consumo é, em princípio, universal e impessoal; a cultura do consumo identifica liberdade com a escolha privada e a vida privada; as necessidades do consumidor são, em princípio, ilimitadas e insaciáveis; A cultura do consumo é um meio privilegiado para negociar a identidade e o status em uma sociedade pós-tradicional; e, por fim, a cultura do consumo representa a importância crescente da cultura no moderno exercício de poder.

Outrossim, Fontenelle (2017) advoga que o termo "cultura do consumo" auxilia em uma compreensão melhor do momento histórico em que vivemos, tendo em vista que consegue entender melhor todas as características do capitalismo, absorvendo o que há de mais amplo na realidade de uma época, incluindo a esfera cultural na esfera das trocas econômicas. No Brasil, pode-se perceber algumas iniciativas no sentido de se avançar na discussão entre cultura e consumo a partir do contexto nacional (PINTO; BATINGA, 2018; PINTO; JOAQUIM, 2021).

O que também pode ser relevante aqui tem a ver com a possibilidade de articular nessa discussão de cultura do consumo alguns elementos da cultura regional, algo que será melhor explanado na próxima seção.

\section{Traços da cultura mineira}

Para falar de cultura mineira, inicialmente, torna-se necessário levar em conta as características do estado de Minas Gerais que, na visão de Diégues Júnior (1960), é composto por diferentes regiões culturais que se formaram a partir de diversas influências. Sendo assim, é possível dividir o estado em, pelo menos, cinco regiões: Região Central; Norte e Nordeste; Triângulo Mineiro; Sul de Minas e Zona da Mata Mineira. Como se trata de uma classificação, inúmeros questionamentos acerca dessa divisão podem ser levantados.

Para Arruda (1999), tentar entender a formação cultural de Minas Gerais é tarefa que deve contemplar a construção histórica do estado. $\mathrm{Na}$ visão dessa pesquisadora, pode-se distinguir dois momentos típicos. O primeiro seria a fase mineradora. $\mathrm{O}$ segundo seria o momento no qual predominam as atividades agrícolas. $\mathrm{O}$ interessante a considerar é que, enquanto a característica marcante do primeiro momento seria o espírito aventureiro, peculiar ao desenvolvimento da mineração, no segundo, existe algo de segurança, estabilidade e trabalho contínuo, pontos importantes das atividades agrícolas.

Além disso, Arruda (1999) enfatiza que diversos povos influenciaram a constituição de uma cultura mineira. Dos negros, o mineiro recebeu a influência da afetividade, da doçura, da fantasia, da fidelidade e da vocação para a música e para as festividades. Dos portugueses, recebeu os sentimentos de amor à família e à terra, a disposição para a parcimônia, a sobriedade, bem como a frugalidade. De habitantes de outras regiões do País também sofreu influências, como a dos paulistas que o mineiro encontrou a altivez, a probidade e a energia envolvida nos empreendimentos, bem como de nortistas e nordestinos, principalmente baianos e pernambucanos, que contribuíram com o entusiasmo, gosto pela dança e pelo bate-papo e amor ao sol e à praia.

Lima (2000) complementa essa visão ao trazer para discussão a questão do mineiro como o "habitante da montanha". Em outras palavras, para esse pesquisador a montanha tem peso como elemento condicionante para a formação do caráter regional do mineiro.

Outra visão que vem a somar à desses pesquisadores é a de Abdala (2007). Para essa autora, a cozinha assume um importante papel na construção da imagem regional mineira. Isso parece ter a ver com a noção de que a culinária mineira 
expressa um espaço privilegiado tanto de convívio como de relações sociais, visto que esse cômodo, juntamente com a copa e o quintal constitui-se o centro do movimento cotidiano da casa mineira.

Contudo, para diversos autores (RIBEIRO, 2006; FREDERICO, 2006; ARRUDA, 1999) fica bastante clara a percepção de que Minas Gerais pertence à cultura caipira. Assim, o estereótipo do mineiro seria aquele indivíduo nascido na zona rural, com hábitos modestos e com falar tímido e pausado. Rocha (2003) levou em consideração três personagens famosos no universo da comédia televisiva para representar o jeito de ser do mineiro:
Nerso da Capitinga, Filomena e Divagar Franco, dois deles eminentemente com perfil caipira. Dessa forma, essa autora constatou que o discurso da mineiridade é apropriado pelos mineiros de diferentes formas. Ou seja, a maneira de ver, viver e assistir são socialmente construídos, o que leva à constatação de que a mineiridade pode ser e é apropriada de forma diversa nas diferentes regiões culturais.

Lourenço (2010), ao investigar as trocas relacionais levando em conta os traços da cultura mineira, buscou sintetizar os mais citados traços culturais mineiros. Essa síntese pode ser visualizada no Quadro 1.

Quadro 1 - Síntese dos traços culturais mineiros por diversos autores.

\begin{tabular}{|l|c|}
\hline \multicolumn{1}{|c|}{ Traços culturais } & Autores \\
\hline $\begin{array}{l}\text { Introspectivo, desconfiado, melancólico, prudente, apegado às tradições, } \\
\text { conciliador, moderado, discreto, paciente, simples, tranquilo, reservado, } \\
\text { modesto, sovina, conservador. }\end{array}$ & Lima (2000) \\
\hline $\begin{array}{l}\text { Destemido, impetuoso, temperamento forte, comedido, tímido, sereno, simples, } \\
\text { apegado às tradições, retraído, prudente, desconfiado, conciliador, introspectivo, } \\
\text { discreto, hospitaleiro, cordial, sovina. }\end{array}$ & Arruda (1999) \\
\hline $\begin{array}{l}\text { Apegado à tradição, valoriza a ordem e a estabilidade, prudente, avesso a } \\
\text { posições extremistas, conciliador, moderado, adaptável, habilidoso, paciente. }\end{array}$ & Dulci (1999) \\
\hline Desconfiado, reservado, dissimulado, prudente, hospitaleiro. & Azevedo (1996) \\
\hline Reservado, de formação clássica e erudita. & Diégues Júnior (1960) \\
\hline $\begin{array}{l}\text { Sóbrio, calmo, astuto, cético, pessimista, sedentário, apegado à tradição } \\
\text { e à rotina, culto excessivo à família, dissimulado, desconfiado. }\end{array}$ & Bojunga (2001) \\
\hline Hospitaleiro, cordial. & Abdala (2007) \\
\hline Desconfiado, afável, hospitaleiro, dissimulado. & Latif (1960) \\
\hline Calado, desconfiado, introvertido, hospitaleiro, inteligente, bom. & Dias (1985) \\
\hline
\end{tabular}

Fonte: adaptado de Lourenço (2010).

Deve-se ressaltar que a articulação entre temas relacionados ao marketing e traços culturais de Minas Gerais é pouco investigada pelos pesquisadores do campo. Uma consulta aos principais veículos de divulgação do conhecimento científico em marketing em nosso País parece corroborar essa afirmação. É possível encontrar os trabalhos de Lourenço (2012), que buscou verificar como os traços culturais mineiros se manifestam nas relações de troca comercial entre funcionários de micro e pequenas empresas varejistas e seus consumidores em municípios de pequeno porte no Sul de Minas Gerais. Outro artigo é o de Pinto e Cruz (2014) cujo objetivo foi investigar as experiências de consumo no Natal em pequenas cidades do interior de Minas Gerais. 


\section{Percurso metodológico}

Em face dos objetivos propostos para o trabalho e da natureza dos fenômenos investigados, o estudo apresenta características exploratórias e descritivas. Dessa maneira, neste trabalho, adotouse uma postura interpretativista de investigação (VERGARA; CALDAS, 2005) que levou à determinação de uma estratégia qualitativa de pesquisa (FLICK, 2004; CRESWELL, 2014).

Pode-se afirmar que o foco central da pesquisa foi buscar um maior entendimento de questões emergentes a partir da articulação entre a cultura do consumo e elementos da cultura regional presentes em uma das principais datas comemorativas do comércio varejista: o Dia dos Namorados (comemorado no dia 12 de junho). A justificativa da escolha dessa data reside no fato de que o Dia dos Namorados contém diversas características simbólicas as quais o tornaria elegível para se investigar as questões propostas. A inspiração para a escolha desta data comemorativa para se estudar os rituais de consumo vieram dos achados da pesquisa conduzida por Ássimos, Pinto e Afonseca (2019), o qual concluiu que o consumo permeia as relações amorosas e que funcionando como expressão do indivíduo permite reconhecer e ser reconhecido, atuando como elemento fundamental de avaliação em momentos de conquista.

Em suas diversas etapas, a pesquisa foi baseada em alguns dos elementos da metodologia da grounded theory na vertente desenvolvida por Charmaz (2009). Entre esses elementos, podem ser citados a amostragem teórica (a qual o pesquisador escolhe os sujeitos de pesquisa não por critérios estatísticos, mas por sua sensibilidade e convicção de que aqueles entrevistados possuem características que serão relevantes para a pesquisa) e a perspectiva indutiva da pesquisa (baseada na noção de que as categorias de análise emergem do campo e não da revisão da literatura).

Quanto à dimensão espacial, investigou-se 10 consumidores (seis mulheres e quatro homens) residentes em Belo Horizonte, Minas Gerais. A idade desses indivíduos variou entre 18 e 27 anos.
Ficou estabelecido que um dos requisitos para participar como respondente da pesquisa seria estar em um relacionamento amoroso há pelo menos seis meses. Todos eles disseram ter, no mínimo, ensino médio completo. As entrevistas (que duraram uma média de 40 minutos cada), foram conduzidas com o auxílio de um roteiro que continha questões organizadas nas seguintes seções: aquecimento (perguntas gerais como idade, formação acadêmica, ocupação anterior e atual, rotina diária e outras); história do relacionamento; significados do Dia dos Namorados; práticas e rituais no Dia dos Namorados; história de vida; e, por fim, fechamento. Esse roteiro de entrevistas foi se transformando ao longo do processo de pesquisa. Começou com questões bem gerais com base em outras pesquisas conduzidas como foco na temática dos rituais de consumo e foi sendo modificado à medida que categorias foram emergindo. A etapa de contato e entrevista aconteceu ao longo do segundo semestre de 2017.

Cabe salientar que as pesquisas foram gravadas e transcritas na íntegra. A partir daí, as entrevistas foram analisadas por meio da técnica de análise de conteúdo, uma vez que se pretendeu identificar o que foi dito a respeito das experiências dos sujeitos no que diz respeito às duas datas comemorativas (BARDIN, 2011). Para essa autora, a análise de conteúdo pode ser entendida como um conjunto de técnicas de análise das comunicações, visando obter, por procedimentos sistemáticos e objetivos de descrição do conteúdo das mensagens, a inferência de conhecimentos relativos às condições de produção/recepção (variáveis inferidas) destas mensagens.

A apresentação e análise dos resultados será conduzida na próxima seção. Os nomes dos entrevistados apresentados nas falas são fictícios.

\section{Análise dos resultados}

A análise do corpus possibilitou a emergência de três categorias de análise quanto aos rituais relativos às comemorações do Dia dos Namorados sob a luz de traços da cultura mineira. São elas: o consumismo atrelado ao Dia dos Namorados; o ato 
de presentear como central no Dia dos Namorados; e as experiências de consumo ligadas ao Dia dos Namorados. Essas categorias serão devidamente analisadas a seguir.

\section{O consumismo atrelado ao Dia dos Namorados}

Fica evidente que a data do Dia dos Namorados tem um apelo muito forte para o consumo por meio da mídia. É muito nítida a relação entre o consumo de presentes, as viagens, as experiências e os rituais de comemoração do Dias dos Namorados. As palavras "presentear", "sair para comemorar", "fazer um programa", entre outras, com o mesmo significado, reforçam essa tendência pelos namorados. Até mesmo aqueles que se dizem à margem do processo de consumo e assumem uma posição crítica no tocante a todos os apelos da mídia acabam remetendo seu discurso para combater essa noção.

Não é escusado afirmar que o Dia dos Namorados é a terceira melhor data para o comércio em questões de faturamento. Dessa forma, como uma "criação" da sociedade de consumo na qual imperam diversas questões diretamente atreladas ao consumismo, não se pode deixar de mencionar que a data ganha contornos diretamente atrelados ao excesso, exagero do consumo ou até mesmo uma distorção do que, de fato, deve ser comemorado na data.

O que faz sentido nesse ponto da análise é que esse excesso de apelo para o consumo que pode tirar a essência do Dia dos Namorados parece incomodar a muitos, porém, esses mesmos indivíduos acabam sendo seduzidos pelas campanhas e aderem ao movimento comum da grande massa de consumidores que é o de dedicar uma boa parte desse dia para atividades de consumo. A entrevistada Bianca ressalta isso em trecho de sua fala.

Eu não tenho apego com data, é mais um dia, na verdade, que fica aquela coisa tipo mercadológica, enchendo o saco, sabe? Que é isso, pra te incentivar a consumir, pra, enfim, gastar o resto do dinheiro que você tem, [risos] (Bianca).
O fragmento de discurso de outra entrevistada (Geisa) também tangencia a ideia de que o Dia dos Namorados foi algo imposto pela sociedade de consumo para fomentar as vendas e aumentar o trânsito de presentes e atividades que não necessariamente estão diretamente ligados aos valores centrais de um relacionamento amoroso.

O que eu menos gosto é ser, tipo, uma data padrão, sei lá por que ter sido escolhida. Não sei, às vezes fica uma obrigação. Sei lá, as pessoas perguntando o que você vai fazer e às vezes você nem quer fazer nada. Naquele dia específico, né? (Geisa).

Do mesmo modo, outra entrevistada também atribui aos excessos do consumo a perda de essência do Dia dos Namorados, tal como as outras datas.

\begin{abstract}
É o mesmo mal de todas as outras datas comemorativas. Você vê demais, as pessoas expondo demais, aquela coisa que eu acho muito não sincera. Igual no Dia das Mães, no Dia dos Pais, as pessoas falam: 'nossa... meu pai, minha mãe eu amo, minha vida não sei o que..., mas nem liga na verdade. E no Dia dos Namorados eu tenho a mesma sensação que as pessoas não necessariamente se importam muito e ficam tentando empurrar para as outras um relacionamento perfeito que obviamente não existe... (Isadora).
\end{abstract}

A entrevistada Isadora, com tom ácido, apresenta uma interpretação que encontra eco nas discussões conduzidas pelos autores críticos da sociedade de consumo. Nesse caso, tanto os namorados quanto o próprio relacionamento estariam assumindo o papel de "mercadorias", ou seja, algo que possa ser tratado como um bem na "gôndola de um supermercado". Complementarmente, essa mesma entrevistada levanta outra questão que extrapola os objetivos do trabalho, quando cita o papel da mídia na valorização do "mundo perfeito", das relações sem problemas. Os rituais de consumo servem para marcar essa posição e aumentar o poder simbólico desse tipo de situação. 
Aí eu acho que é essa inversão, né? De, em vez de o carinho, a atenção, o cuidado, você dar alguma coisa ou um presente físico assim. Mas eu acho que é essa inversão, sabe? Do que que é o sentimento, é... capitalizar o sentimento assim. Eu não gosto disso, eu acho que esse consumismo exacerbado é o que atrapalha. (Bianca).

A visão de que o Dia dos Namorados é cercado de uma série de arranjos de consumo faz parte do excerto. A entrevistada amplia essa percepção para todas as datas comemorativas, incluindo Dia das Mães, Dia dos Pais, e outros. A entrevistada também parece descortinar outra questão que tem a ver com a construção de imagem que, não raramente, não condiz com a realidade. Ou seja, tentar passar a ideia de relacionamentos perfeitos, sem problemas, sem atritos e desencontros parece fazer parte do ideário do Dia dos Namorados reforçado pelas campanhas publicitárias. Como não poderia deixar de ser diferente, o consumo perpassa todas essas noções, pois é a forma pela qual os indivíduos vão reforçar todos os estereótipos veiculados nas campanhas.

Os excessos acabam gerando uma série de problemas que acabam por gerar angústia, insatisfação e frustrações.

E Dia dos Namorados pra mim acabou virando essa coisa de marketing. De dia cheio, de trânsito ruim, de caos na cidade, e que é difícil você, por exemplo, conseguir ir em algum restaurante sem estar cheio de pessoas e de, tipo, amigas reclamando que estão sozinhas assim. Isso ai é também muito grande. Então é um dia, na verdade, mais dramático. (Bianca).

Eu penso em promoções nos shoppings. É o que vem na minha cabeça, porque tem um tanto, né? Inclusive, a gente aproveita para comprar coisas, não necessariamente pra dar de presente, mas a gente já estava pensando em comprar no Dia dos Namorados por causa das promoções. (Isadora).

Não se pode deixar de mencionar que a categoria emergente mais marcante ao longo tanto do processo de coleta de dados como de análise dos resultados remete à questão do ato de presentear como central na comemoração do Dia dos Namorados. Se a questão tem relação com a cultura do consumo também merece uma discussão à parte, a qual será conduzida no próximo tópico.

\section{$O$ ato de presentear como algo central no Dia dos Namorados}

Os presentes se mostraram como via de expressão tangível que se apresentam para demarcar diferentes momentos não só da relação, mas como indicador de sentimentos, de intenções, de sensibilidade, entre outros. Cabe comentar que o presente apresenta alguns elementos que fazem sentido para o casal, ou seja, o que para outras pessoas pode parecer algo banal e simples, para os dois namorados representa uma série de significados. Entre esses significados podem ser citados a data em que ambos se conheceram, como começaram a namorar, reflete gostos de ambos, desejos para o futuro. O presente no Dia dos Namorados acaba assumindo esse papel essencial de tangibilizar o sentimento, tal como expresso nas falas das entrevistadas Denise e Isadora.

Querendo ou não, quando você dá presente pra pessoa você mostra que você se importa. E quando você dá um presente que combina com ela, você mostra que você se importa mais ainda, tipo assim. (Denise).

$O$ ato de lembrar do presente em si, porque é uma lembrança, né? O detalhe da gente ter que parar.. a gente corre o dia todo, né? Você para o seu tempo pra ter que ir lá, escolher alguma coisa pra dar para alguém. E, também, o cuidado de querer escolher alguma coisa que eu vá gostar. (Isadora).

O mesmo pode ser verificado nos comentários de Evaldo e de Abílio quando eles ratificam a ideia de que o que conta no presente é a intenção, o esforço, a busca do parceiro em conseguir pensar em algo que consiga agradar o outro.

Eu gosto muito mais da intenção do que o presente, assim. (Abílio). 
Aquele que tem muito carinho dentro dele, assim, não é só a coisa material, porque se a pessoa pensou, pesquisou e buscou pra te agradar mesmo, isto já me deixa muito feliz. Só de saber que ela procurou e tal. (Evaldo).

A primeira questão que merece escrutínio tem a ver com a inspiração para a escolha do presente. Nesse caso, ganha muita força a importância da intenção, de oferecer para o outro algo que não foi somente comprado, mas elaborado e confeccionado, às vezes de forma manual, por um dos namorados. Enquanto o entrevistado Felipe ressalta a importância da intenção, o entrevistado Carlos enfatiza que a característica da personalização, do cuidado em dar "uma cara" especial do presente de acordo com o gosto do outro. A mesma forma de pensar no tocante à personalização do presente foi mencionada por Denise.

A intenção. Eu acho que o que mais vale realmente é a intenção de dar no Dia dos Namorados. Então dá, e ela me deu uma coisa que eu tava precisando muito que era uma bermuda na época e eu tava precisando muito. Então assim, dá com um bom coração, com intenção boa, sabe? Não é simplesmente dar um presente porque é Dia dos Namorados, dá com um objetivo, vamos dizer assim. (Felipe).

Agora eu acho que uma coisa feita à mão representa mais, porque você teve o trabalho de fazer, a delicadeza, o cuidado, você teve todo o carinho do mundo pra fazer a coisa. Não é só entregar o dinheiro e comprar. Então o que não pode faltar nesse dia é algo feito à mão. Como eu te disse, né? Um potinho com quase 200 fitilhos. (Carlos).

E ai eu fui fazendo tudo, sabe? Foi um presente, tipo, que eu construi tudo. Eu escolhi as imagens. Eu que mandei na gráfica. Imprimi, peguei na gráfica. Fui no lugar dos quadros. Peguei a imagem e coloquei dentro dos quadros, sabe? Embalei tudo bonitinho. (Denise).

O último excerto, retirado do discurso da entrevistada Denise, merece uma análise especial. Percebe-se que ela dá informações pormenorizadas acerca de como ela personalizou o presente, retratando o cuidado em cada detalhe para agradar ao parceiro. Ainda que o presente era algo simples quando comparado a um bem sofisticado e com valor monetário, nesse caso o simbólico assumiu o protagonismo. Ou seja, desde a elaboração da ideia, passando pela confecção do produto até chegando à embalagem, o presente foi ganhando camadas de significados, o que o torna insubstituível, algo que merece toda uma atenção pelos pesquisadores do gift-giving.

A obrigatoriedade de dar algo ou a necessidade de cumprir uma obrigação também foram citadas como algo negativo no ato de presentear, e caso haja essa suspeita por parte de um dos parceiros, isso acaba gerando um sentimento de frustração e tristeza. Bianca, uma das entrevistadas com postura mais crítica frente aos excessos proporcionados pelo comércio quanto às datas comemorativas chega a enfatizar que "...eu não gosto de pensar nessa obrigatoriedade de dar um presente físico assim...".

Dito de outra forma, o presente, tal como expresso pelos entrevistados, precisa refletir atributos que fogem do normal, do esperado, do trivial, assumindo características especiais e que só fazem sentido quando estão de acordo com algo que representa a relação entre os dois amantes. A questão de oferecer algo que seja surpreendente ou faça surgir o sentimento de surpresa também emergiu nas entrevistas.

Eu acho lindo este romantismo, igual quando ele me deu a minha aliança. Ele trouxe um buquê, aí dentro do buquê tinha uma... eu sou lerda, muito lerda... uma rosinha, tipo, de plástico, meio de veludo em cima e dentro dela tinha uma aliança, mas até eu descobrir isto, foi um custo. E ai ele colocou uma caixinha com um colar, dentro do buquê. Não vi nem caixinha e nem a flor que não era. Aí, ele foi falou assim: 'você não viu aqui não?'(Heloisa).

Eu gosto também quando ela faz alguma surpresa assim, que eu não tô esperando, tipo trem de lingerie, assim. Alguma coisa assim. (Abílio).

Fica implícita em vários dos excertos apresentados a importância que o presente assume no Dia dos Namorados. Ou seja, tal como entendido 
por Wolfinbarger e Gilly (1996), os objetos que assumem o papel de presentes em uma situação como o Dia dos Namorados vão além de suas funções restritamente econômicas para adquirirem uma função de extensões do próprio doador e receptor.

Essa discussão, do ponto de vista teórico, perpassa duas bases teóricas. Uma evidentemente está relacionada ao tema do gift-giving, ou presentear, em português. O outro tem a ver com a questão da cultura material que estabelece as interlocuções entre o campo da Antropologia e os estudos do consumo, que joga luz sobre a relação entre os indivíduos e os objetos.

Quanto ao primeiro tema - gift-giving - o presente estudo traz algumas contribuições interessantes pois traz à baila a perspectiva ritualística presente nas comemorações do Dia dos Namorados para o ato de presentear. Tal como discutido por Belk e Coon (1993), o ato de presentear e o presente em si indica a demonstração de um desejo que é tangibilizado pelo bem apresentado. O motivo que move o ato de presentear é a oportunidade de expressar sentimentos, tornando-se expressões dos relacionamentos pessoais. Outrossim, Belk (1979) enfatiza que os presentes têm o poder de simbolizar as conexões entre as pessoas, o que acaba por dar a eles um significado especial.

No tocante à temática da cultura material, é importante lançar mão de autores como Miller (2013, p. 12) que se dedica a entender como os objetos constroem sujeitos e "como e por que uma apreciação das coisas nos levará a uma apreciação mais profunda das pessoas". Dito pelo autor de outra forma, "a melhor maneira de entender, transmitir e apreciar nossa humanidade é dar atenção à nossa materialidade fundamental" (MILLER, 2013, p. 10). No caso do Dia dos Namorados, o presente representa essa relação que vem sendo construída pelo casal no relacionamento, algo que também foi verificado na pesquisa focada nos rituais de consumo em relacionamentos amorosos conduzida por Reinhardt e Alecrim (2021) e na investigação empreendida por Ássimos, Pinto e Afonseca (2019).

A partir da análise das entrevistas, outras questões também emergiram. Fica evidente que a finalidade do presente está no estabelecimento de um vínculo entre quem presenteou e o presenteado. Esse vínculo se concretiza e acaba tendo um reforço no ato da troca de presentes, o que caracteriza uma forma de ritual tal como proposto por Rook (2007) e McCracken (2003). A importância de receber presentes é mais valorizada pelas mulheres que atrelam o presente e as nuances envolvidas ao nível de consideração e comprometimento do parceiro com o relacionamento ante ao discurso dos homens que não se mostram tão preocupados com $o$ ato de receber presentes.

Outro ponto que também marca a análise no tocante ao presente é que não há uma unanimidade entre os entrevistados quanto ao que é um bom presente. Fica claro que alguns objetos têm características mais aderentes às comemorações do Dia dos Namorados, como chocolates, bombons e ursinhos de pelúcia, mas também foram citadas viagens a dois, um programa a dois especial, como um jantar especial e, como dito anteriormente, principalmente, objetos personalizados. Ainda que os bens tangíveis tenham seu valor, não se pode deixar de levar em conta o papel de destaque de itens ligados aos serviços, como de restaurantes, no caso de comida, e de turismo, como citado por diversos entrevistados.

Esse ponto merece um aprofundamento à luz da literatura de consumo com contornos de elementos da cultura material. Torna-se interessante iniciar a construção da discussão a partir do que propõe Campbell (2004) ao advogar a favor da emergência de um novo tipo de consumidor - o que ele vai chamar de consumidor artesão, que seria uma nova proposta frente às três imagens visualizadas anteriormente por meio de metáforas que prevaleceram na literatura das Ciências Sociais sobre consumo até o início do século XXI: o consumidor herói, o consumidor tolo e o consumidor pós-moderno. Com relação ao primeiro - herói representa o consumidor como ator ativo, típico da teoria econômica, que calcula e raciocina, buscando a maximização de recursos. Já o consumidor tolo é aquele passivo, manipulado, explorado, ou seja, um "fantoche" à mercê das forças do mercado. Por fim, 
o consumidor pós-moderno seria aquele que funciona como um manipulador dos significados simbólicos vinculados aos produtos. A partir dessas três imagens, entraria em cena o que Campbell (2004) chama de consumidor artesão, que é aquele que consome principalmente por um desejo de tomar parte em atos criativos de expressão de sua individualidade (CAMPBELL, 2004, p. 46).

$\mathrm{O}$ que essa discussão quer reforçar é a ideia de que nos casos ilustrados a partir da pesquisa se delineia um tipo de consumidor que tem grande aderência ao que é estabelecido pelo autor. $\mathrm{Ou}$ seja, os pontos de contato entre os achados e o que defende o autor é que "o consumidor artesão é alguém que transforma 'mercadorias' em objetos personalizados, ou, poder-se-ia dizer, 'humanizados"” (CAMPBELL, 2004, p. 50), o que parece fazer todo o sentido no ato de presentear no Dia dos Namorados. Esse pode ser considerado um achado interessante do trabalho que traz contribuições para a literatura, tanto ligado ao consumo como de vida social das coisas.

Outrossim, o que está descrito até aqui também parece ter interlocução com os denominados processos de singularização propostos por Kopytoff (2008). Para esse autor, "as mercadorias devem ser não apenas produzidas materialmente, mas também culturalmente sinalizadas como um determinado tipo de coisas" (p. 89). Em suma, ao propor e "construir" um presente especial, por meio dos rituais os namorados acabam sinalizando contextos e dando uma dimensão não material e espiritual ao objeto, tornando-o singular para ambos os amantes.

Os entrevistados também criticam o fato de não ter a oportunidade de comemorar o Dia dos Namorados quando o dia 12 de junho cai no meio da semana, o que acaba motivando muitos a ter que conduzir as comemorações no próximo final de semana. Se utilizar o final de semana pode favorecer a um maior planejamento e cuidado para comemorar a data, por outro lado, acaba por tirar a aura de romantismo existente no dia 12 de junho quando muitos restaurantes, motéis e outros estabelecimentos concedem promoções, criam programações especiais e se dedicam a fazer decorações especiais.
Tudo isso parece remeter às noções atinentes ao consumo experiencial, temática que será discutida no tópico a seguir.

\section{As experiências de consumo ligadas ao Dia dos Namorados}

Diretamente relacionadas ao consumo nas comemorações do Dia dos Namorados, as experiências de consumo emergiram com destaque ao longo das entrevistas e da etapa de análise dos dados. Como já enfatizado na discussão da categoria anterior, no Dia dos Namorados, além dos presentes tangíveis tradicionais ligados ao romantismo, as experiências de consumo permeiam e fazem parte do roteiro dos rituais. Nesse sentido, os entrevistados, quase sempre, enfatizavam a importância do restaurante, do hotel, da viagem, e junto com essas citações emergiam questões essencialmente experienciais, como aquelas atreladas aos cinco sentidos e aos sentimentos como alegria, fantasia e emoções diversas. É importante considerar que todos esses sentimentos e emoções parecem estar diretamente atrelados à data. As seguintes citações expressam isso.

Ou vamos supor, num lugar friozinho, gostoso; não, praia não. Acho que num lugar friozinho, gostoso, que dê pra você tomar vinho, conversar, comer alguma coisa gostosa. Eu gosto muito de sair pra comer muito. E com música legal. (Denise).

Algumas coisas diferentes, porque a gente gosta muito de aventuras assim, em todos os sentidos. Então, ir pra algum lugar que a gente pode andar, explorar, ter contato com a natureza e tudo; e à noite, depois do conforto, de tá juntos, num lugar aconchegante, confortável, um jantar, uma comida gostosa. (Abílio).

Percebe-se em ambas as citações dos entrevistados a noção experiencial. Ambos tentam enfatizar em seus discursos o que é considerado agradável para eles para comemorar o Dia dos Namorados. Denise, por exemplo, lança mão da palavra "gostoso" por três vezes em pouco tempo, ligando-a à ideia de aconchego, temperatura 
agradável e música, compondo uma "atmosfera" propícia para o romance. O mesmo se percebe no discurso do entrevistado Abílio que, assim como a Denise, também relaciona esse bom momento de romantismo com um local aconchegante e confortável acompanhado de uma comida gostosa.

Esses achados da pesquisa guardam uma importante relação com a literatura de experiências de consumo, notadamente os apontamentos de Pullman e Gross (2003). Para esses pesquisadores, a criação de experiências deve considerar contextos que podem ser definidos em um contexto físico, um contexto relacional e um determinado período de tempo. Isso pode ser complementado com a ideia de Bruner (1986), o qual enfatiza a importância de entender que a experiência emerge em um ambiente em que o indivíduo exerce um papel importante, pois ele próprio tem condições não apenas de se envolver, mas, principalmente, de moldar sua ação.

Outros fragmentos de discursos reforçam essa questão das experiências de consumo como fundamentais para o Dia dos Namorados e além dos tradicionais presentes tangíveis.

Seria num hotel fazenda, que eu adoro comer também. Então, seria num lugar lindo, maravilhoso, que eu pudesse comer o dia inteiro, $e$ com piscina. Era para ser perfeito, né? Então que tivesse uma praia também, que eu saísse à noite. (Heloísa).

Uma praia mais tranquila, sem muita gente, senão também você não consegue fazer nada. Com música legal, com coisa de comer, assim, sempre, uma cerveja, dançar junto, porque a gente gosta muito de dançar. Então, assim, a gente vai para... um axé, uma festa, dançando junto com pessoas em volta. (Juliana).

Nos trechos das falas das duas entrevistadas é interessante enfatizar que o ambiente de descontração e quase sempre ligado à praia faz parte do ideário de comemoração de um bom Dia dos Namorados. Cabe ressaltar ainda a menção à questão da comida que aparece com destaque no discurso das entrevistadas. Algo idêntico pode ser verificado no trecho da fala do entrevistado Felipe.
Viajaria. Eu acho que eu viajaria, pra algum lugar bem tranquilo. Pra uma serra, uma praia. Então, assim, levaria só o que precisasse pra passar uns dois dias, três dias. Acho que seria basicamente isso, me isolar um pouco com minha namorada, entendeu? Vamos pra praia, vamos pra serra, vamos pra alguma pousada, só nós dois, um ou dois dias. (Felipe).

A fim de sumarizar os principais achados dessa análise, percebeu-se que os rituais de comemoração do Dia dos Namorados são permeados por questões culturais e que, como tais, (re)significam essa data a todo momento, operando em um contexto marcado pela cultura de consumo, que culminam na presença marcante da troca de presentes e nas experiências extraordinárias de consumo.

Assim, o trabalho parece estar alinhado às ponderações conduzidas por Epp e Price (2008) ao incentivar os pesquisadores do consumo a enveredarem pelo caminho dos estudos de família. Essas autoras enfatizam a importância de se entender como se dão as diversas relações no seio da família em questões envolvendo o consumo que perpassem formas de comunicação diversas, como rituais, narrativas, dramas sociais e ainda as influências intergeracionais.

\section{Considerações finais}

A discussão dos resultados conduzida na seção anterior permite apontar algumas conclusões gerais sobre a pesquisa. $\mathrm{O}$ discurso dos entrevistados confirma a ideia de que o Dia dos Namorados é carregado de sentimentos positivos, característicos do romantismo envolvendo a data, algo que é representado pela presença marcante das palavras "afeto", “atenção", "cuidado", "amor", "carinho", "sentimento", entre outras. Ao mesmo tempo, percebeu-se a presença destacada de atos e comportamentos ligados à presença de presentes, e aspectos experienciais diretamente atrelados a todos esses sentimentos, o que ratifica a noção de que a cultura do consumo também permeia essa data. Embora alguns entrevistados assumam uma postura mais crítica no tocante à data, ressaltando 
os efeitos negativos da publicidade que exacerba o consumismo, por outro lado também fica evidente que todos acabam se deixando levar pelos apelos dos produtos e serviços voltados para essa data. Vale enfatizar que a troca de presentes assumiu um papel simbólico fundamental na data. Isso está em linha com a literatura de gift-giving, a qual ratifica a ideia de que os presentes assumem o papel de um “operador" das relações amorosas. Emergiu ainda das análises a temática das experiências de consumo que se mostrou muito aderente às comemorações dos amantes, tendo em vista a preferência dos indivíduos para os aspectos intangíveis que vão além dos presentes tradicionais.

Outro achado interessante descrito e analisado no capítulo anterior remete a alguns elementos marcantes relativos à literatura da cultura material que advogam a favor da vida social das coisas. Quando os namorados buscam a personalização de seus presentes para que possam fazer sentido no contexto ao qual o relacionamento se desenrola, esse bem ganha contornos que vão muito além de seu valor funcional.

O confronto desses achados com a literatura que discute traços da cultura mineira traz algumas contribuições úteis para o campo. Questões ligadas aos traços de apego às tradições, à parcimônia, à sobriedade, bem como à frugalidade, típicos da cultura mineira, fizeram parte de toda a discussão.

Ainda que a característica principal dessa pesquisa tenha sido explorar a temática e, assim, apresentar pontos que possam ser aprofundados em pesquisas futuras, é importante ressaltar que os resultados discutidos lançam luz sobre possíveis contribuições para as empresas, principalmente aquelas dos setores varejista e de serviços. Embora haja todo um esforço dos varejistas e dos ofertantes de serviços que tentam explorar de forma mais adequada a data, os resultados do estudo trazem à baila alguns elementos que poderiam ajudar a se planejar estratégias mais alinhadas. Por exemplo, no tocante aos presentes, os namorados foram unânimes em afirmar que a personalização, a construção de algo mais "artesanal" tem um valor simbólico muito maior ante um presente mais caro. Assim, as empresas poderiam investir mais, não somente na confecção de produtos com essas características, mas reforçar a comunicação dos produtos nesse sentido. Da mesma forma, os ofertantes de serviços poderiam também explorar mais essa questão no momento de estabelecer suas estratégias de serviços atrelados ou não a produtos tangíveis.

Nesse ponto, torna-se adequado jogar luz sobre algumas limitações que foram percebidas ao longo do processo de pesquisa. A primeira limitação que emerge, tendo por base a característica do estudo, está relacionada à alta dose de subjetividade da pesquisa. Embora nessa pesquisa todo o processo tenha sido conduzido por um grupo, ainda que pequeno, de pesquisadores, pode-se dizer que o risco de as interpretações possuírem vieses e reflexos de ideologias e interesses pessoais é considerável. Esses vieses podem estar (e ficaram) presentes nas diversas fases da pesquisa, seja na elaboração dos roteiros de entrevistas, na condução das entrevistas, na percepção dos pesquisadores na coleta de detalhes nos diários de campo, na forma e na descrição de codificação das variáveis, seja, evidentemente, no trabalho de análise dos resultados.

Quanto às recomendações para estudos futuros, muitas são as sugestões, até mesmo porque o objetivo de um estudo exploratório e com uma perspectiva tão aberta e ampla como este trabalho não é escusado afirmar que os pesquisadores estão terminando a pesquisa com mais indagações do que quando comparado com as etapas iniciais. Pode-se dizer que no que tange ao ato de presentear, os resultados do trabalho apresentaram algumas lacunas, principalmente quanto à relação entre presentes e cultura material. A literatura mostra-se com gaps nesse sentido que poderiam ser preenchidas com estudos conduzidos, seja no contexto de datas comemorativas ou em qualquer outra situação de consumo na qual o ato de presentear é marcante. Tal como discutido na seção de análise de dados, emergiu a noção experiencial do consumo diretamente atrelada ao gift-giving. É importante ressaltar que essa também se constituiu em uma lacuna na literatura da temática que pode ser explorada em 
estudos futuros. Ainda que traços da cultura mineira tenham sido o foco do trabalho, por se tratar de uma temática tão ampla e rica, outros estudos podem avançar na direção de entender melhor o ato de presentear à luz da cultura.

\section{Referências}

ABDALA, M. C. Receita de mineiridade: a cozinha e a construção da imagem do mineiro. 2. ed. Uberlândia: UFU, 2007.

ARRUDA, M. A. N. Mitologia da mineiridade: o imaginário mineiro na vida política e cultural do Brasil. São Paulo: Brasiliense, 1999.

ARVIDSON, A. The function of cultural studies in marketing: a new administrative science? In: TAKAJEWSKI, M.; BROWNLIE, D. Critical marketing: issues in contemporary marketing. London: John Willey, 2008. p. 329-344.

ÁSSIMOS, B. M.; PINTO, M. R.; AFONSECA, S. M. O consumo e suas articulações com os relacionamentos amorosos. Revista Ciências Administrativas, Fortaleza, v. 25, n. 3, p. 1-16, 2019.

AZEVEDO, F. A cultura brasileira: introdução ao estudo da cultura do Brasil. 6. ed. Rio de Janeiro: UFRJ, 1996.

BARBOSA, L. Apresentação. In: BARBOSA, L.; CAMPBELL, C. (org.). Cultura, consumo e identidade. Rio de Janeiro: Ed. FGV, 2006.

BARBOSA, L.; CAMPBELL, C. (org.). Cultura, consumo e identidade. São Paulo: Ed. FGV, 2006.

BARDIN, L. Análise de conteúdo. São Paulo: Edições 70, 2011.

BELK, R. W. Gift-giving behavior. In: SHETH, J. N. Research in marketing. $2^{\text {nd }}$ ed. Greenwich, CT: JAI Press, 1979. p. 95-126.

BELK, R. W.; COON, G. Gift giving as agapic love: an altemative to the exchange paradigm based on dating experiences. Journal of Consumer Research, Oxford, v. 20, n. 3, p. 393-416, 1993. Doi: http://dx.doi.org/10.1086/209357

BOJUNGA, C. JK: o artista do impossível. Rio de Janeiro: Objetiva, 2001.
BRUNER, E. W. Experience and its Expressions. In: TURNER, V. W.; BRUNER, E. M. (ed.). The anthropology of experience. Urbana: University of Illinois Press, 1986.

CAMPBELL, C. O consumidor artesão: cultura, artesania e consumo em uma sociedade pósmoderna. Antropolítica, Rio de Janeiro, n. 17, p. 45-67, 2004.

CHARMAZ, K. A construção da teoria fundamentada: guia prático para análise qualitativa. Porto Alegre: Artmed, 2009.

CRESWELL, J. W. Investigação qualitativa \& projeto de pesquisa: escolhendo entre cinco abordagens. 3. ed. Porto Alegre: Penso, 2014.

DALMORO, M. Construção de significados culturais: uma análise do mercado de suco de uva orgânico. Revista Brasileira de Marketing, São Paulo, v. 14, n. 1, p. 97-109, 2015. Doi: https://doi. org/10.5585/remark.v14i1.2734

DESJEUX, D. O consumo: abordagens em ciências sociais. Maceió,AL: Edufal, 2011.

DIAS, F. C. Mineiridade: construção e significado atual. Ciência \& Trópico, Recife, v. 13, n. 1, p. 7389, 1985.

DIÉGUES JÚNIOR, M. Regiões culturais do Brasil. Rio de Janeiro: Centro Brasileiro de Pesquisas Educacionais, 1960.

DOUGLAS, M.; ISHERWOOD, B. O mundo dos bens: para uma antropologia do consumo. Rio de Janeiro: Ed. UFRJ, 2006.

DULCI, O. S. Política e recuperação econômica em Minas Gerais. Belo Horizonte: UFMG, 1999.

EPP, A. M.; PRICE, L. L. Family Identity: A Framework of Identity Interplay in Consumption Practices. Journal of Consumer Research, Oxford, v. 35, n. 1, p. 50-70, 2008. Doi: http://dx.doi. org/10.1086/529535

FLICK, U. Uma introdução à pesquisa qualitativa. 2. ed. Porto Alegre: Bookman, 2004.

FONTENELLE, I. A. Cultura do consumo: fundamentos e formas contemporâneas. São Paulo: Ed. FGV, 2017. 
FREDERICO, E. Y. O caipira e os outros. In: BOSI, A. (org.) Cultura brasileira: temas e situações. 4. ed. São Paulo: Ática, 2006. p. 103-113.

KOPYTOFF, I. A biografia cultural das coisas: a mercantilização como processo. In: APPADURAI, A. A vida social das coisas: as mercadorias sob uma perspectiva cultural. Niterói: Ed. UFF, 2008.

LACERDA, C. C. O.; PAIVA JÚNIOR, F. G.; MELLO, S. C. B. Era um Biquíni de Bolinha Amarelinha tão Pequenininho: análise de um artefato cultural de moda e sua [re]significação a partir dos estudos culturais. Revista Interdisciplinar de Gestão Social, Salvador, v. 9, n. 2, p. 83-113, 2020. Doi: http://dx.doi.org/10.9771/23172428rigs. v9i2.33985

LATIF, M. B. As minas gerais. Rio de Janeiro: agir, 1960.

LIMA, A. A. Voz de Minas: ensaio de sociologia regional brasileira. 4. ed. Rio de Janeiro: Vozes, 2000 .

LOURENÇO, C. D. S. As trocas relacionais no mercado consumidor sob a ótica da cultura brasileira e mineira. 2010. 295 f. Tese (Doutorado em Administração) - Universidade Federal de Lavras, Lavras, 2010.

LOURENÇO, C. D. S. Cultura regional mineira e relações comerciais: um estudo etnográfico no varejo. In: ENCONTRO DA DIVISÃO DE MARKETING DA ANPAD - EMA, 5., 2012, Curitiba. Anais [...]. Curitiba: ANPAD, 2012.

LUIZ, G. V.; TEIXEIRA, K. M. D.; SILVA, N. M.; GUERRA, F. F. Capital cultural e consumo de bens culturais em famílias nucleares. Revista Economia \& Gestão, Belo Horizonte, v. 18, n. 51, p. 6376, 2018. Doi: https://doi.org/10.5752/P.19846606.2018v18n51p62-76

McCRACKEN, G. Cultura e consumo: novas abordagens ao caráter simbólico dos bens e das atividades de consumo. Rio de Janeiro: Mauad, 2003.

MIGUELES, C. Antropologia do consumo: casos brasileiros. Ed. FGV, 2007.

MILLER, D. Trecos, troços e coisas: estudos antropológicos sobre a cultura material. Rio de Janeiro: Jorge Zahar, 2013.
PINTO, M. R.; BATINGA, G. L. Cultura e consumo no Brasil: estado atual e novas perspectivas. Belo Horizonte: Ed. PUC-Minas, 2018.

PINTO, M. R.; CRUZ, R. C. Experiências de consumo no Natal de cidades do interior de Minas Gerais. Gestão \& Regionalidade, v. 30, n. 89, p. 35-48, 2014. Doi: https://doi.org/10.13037/ gr.vol30n89.1918

PINTO, M. R.; JOAQUIM. A. M. Cultura e consumo no Brasil: avançando em novas articulações. Belo Horizonte: Ed. PUC-Minas, 2021.

PULLMAN, M.; GROSS, M. Welcome to your experience: where you can check out anytime you'd like, but you can never leave. Journal of Business \& Management, San Luis, CA, v. 9, n. 3, p. 215-232, 2003.

REINHARDT, J. S.; ALECRIM, T. R. Análise do ritual de presentear dentro de relacionamentos amorosos. In: PEREZ, C; TRINDADE. E. (org.). Cultura (i)material e rituais de consumo: perspectivas semiopsicanalíticas. São Paulo: ECA-USP, 2021.

RIBEIRO, D. O povo brasileiro: a formação e o sentido do Brasil. São Paulo: Companhia de Bolso, 2006.

ROCHA, S. M. Identidade regional, produção e recepção: a "mineiridade" na televisão. Semiosfera, Rio de Janeiro, v. 3, n. 4/5, p. 1-12, 2003.

ROOK, D. Dimensão ritual do comportamento de consumo. Revista de Administração de Empresas, Rio de Janeiro, v. 47, n. 1, p. 81-98, 2007. Doi: http:// dx.doi.org/10.1590/S0034-75902007000100013

SALOMÃO, M. T.; MORAES, S. G.; ROCHA, M. B. P.; STREHLAU, V. I. Disposições do consumidor em contextos multiculturais: uma proposta de organização conceitual. Revista Brasileira de Marketing, São Paulo, v. 19, n. 3, p. 683-704, 2020. Doi: https://doi.org/10.5585/remark.v19i3.15410

SLATER, D. Cultura do consumo e modernidade. São Paulo: Nobel, 2002.

VERGARA, S. C.; CALDAS, M. P. Paradigma interpretativista: a busca da superação do objetivismo funcionalista nos anos 1980 e 1990. Revista de Administração de Empresas, Rio de Janeiro, v. 45, n. 4, p. 66-72, 2005. 
WOLFINBARGER, M. F.; GILLY, M. C. An experimental investigation of self-symbolism in gifts. Advances in Consumer Research, St. Louis, v. 23, p. 458-462, 1996.

\section{Agradecimentos}

Os autores agradecem à Fundação de Amparo à Pesquisa do Estado de Minas Gerais (Fapemig) pelo apoio financeiro à pesquisa. 